Dingman, W., and Sporn, M. B. (1961). f. psychiat. Res., 1, 1.

Edwin, E., Holten, K., Norvum, K. R., Schrumpf, A., and Skaug, O. E. (1965). Acta med. scand., 177, 689.

Eysenck, H. J. (1959). Manual of the Maudsley Personality Inventory. London.

Ferraro, A., Arieti, S., and English, W. H. (1945). 7. Neuropath. exp. Neurol., 4, 217 .

Hansen, T., Rafaelsen, Ole J., and Rødbro, P. (1966). Lancet, 2, 965.

Helsborg, H. C. (1958). Act a psychiat. scand., 33, 303.

Henderson, J. G., Strachan, R. W., Swanson Beck, J., Dawson, A. A., and Daniel, M. (1966). Lancet, 2, 809.

Holmes, J. MacD. (1956). Brit. med. f., 2, 1394.

Hunter, R., and Matthews, D. M. (1965). Lancet, 2, 738

Kendrick, D. C. (1964). Psychol. Rep., 15, 188.

- (1965). Brit. F. Soc. clin. Psychol., 4, 141. Parboosingh, R., and Post, F. (1965). Ibid., 4, 63.

Kilpatrick, G. S. (1961). Brit. med. f., 2, 1736

Klerman, G. L. (1966). Int. 7. Psychiat., 2, 73.

McAlpine, D. (1929). Lancet, 2, 643.
Neill, D W., and Weaver, J. A. (1958), Brit. 7. Haemat., 4, 447.

Nieweg, H. O., Van Buchem, F. S. P., and Kroese, W. F. S. (1952). Acto med. scand. 142,45

Raven, J. C. (1958). Guide to Using the Mill Hill Vocabulary Scale with the Progressive Matrices Scales. London

Samson, D. C., Swisher, S. N., Christian, R. M., and Engel, G. L. (1952) Arch. intern. Med., 90, 4.

Scheinberg, P. (1951). Blood, 6, 213.

Shulman, R. (1967a). Brit. F. Psychiat., 113, 241

- (1967b). Ibid., 113, 252

Siegel, S. (1956). Non-Parametric Statistics: For the Behavioural Sciences. New York.

Stewart, M. A., Drake, F., and Winokur, G. (1965). Dis. nerv. Syst., 26 479.

Strachan, R. W., and Henderson, J. G. (1965). Quart. F. Med., 34, 303.

Thomas, E. D., and Lochte, H. L. (1958). F. clin. Invest., 37, 166.

Walton, J. N., Kiloh, L. G., Osselton, J. W., and Farrall, J. (1954) Electroenceph. clin. Neurophysiol., 6, 45.

Young, R. H. (1932). F. Amer. med. Ass., 99, 612.

\title{
Stenosis and Occlusion of Vessels in Cerebral Infarction
}

\author{
S. K. BATTACHARJI,* M.B., CH.B., PH.D. ; E. C. HUTCHINSON,* M.D., F.R.C.P. ; \\ A. J. MCCALL,* M.D., F.R.C.P., F.C.PATH.
}

Brit. med. F., 1967, 3, 270-274

The contribution of cerebral vascular disease to the morbidity and mortality of an ageing population has led to a notable increase in studies of the condition in many branches of medicine. Stenosis and occlusion of the extracranial part of the cerebral blood supply has been the subject of several pathological studies (Hutchinson and Yates, 1957 ; Duffy and Jacobs, 1958 ; Martin et al., 1960 ; McGee et al., 1962). Schwartz and Mitchell (1961) reported on the results of a study of the neck vessels in 93 unselected necropsies. They showed that atheroma of the neck vessels increased with age in all patients and that stenosis of severe degree may occur without evidence of cerebral infarction. On their findings they accepted a direct relation between thrombotic occlusion of neck vessels and cerebral infarction but felt that the significance of stenosis in this context was uncertain.

This communication concerns part of a study of the pathology of cerebral infarction and reports the prevalence of stenosis and occlusion of the cerebral arteries in a series of patients with cerebral infarction and compares these findings with an unselected series of patients who died of unrelated causes.

\section{Material and Methods}

The material for the study was obtained from 145 necropsies performed at the North Staffordshire Royal Infirmary. During the time of the investigation all 57 cases found to have a cerebral infarct were included in the infarct group. Cases of emboli obviously arising from the heart and cases of paradoxical embolism were excluded. The control group consisted of 88 cases where there was no evidence of cerebral infarction and the age at death was over 45 . No deliberate selection was made, but as it was not always possible to remove the cervical spine in a particular case coming to necropsy the cases were not consecutive.

The brain was removed and fixed in $10 \%$ formalin in the routine manner. The arch of the aorta was divided above the

* North Staffordshire Royal Infirmary, Stoke-on-Trent.

Dr. Battacharji was awarded the Ph.D. at the University of Birmingham for a thesis entitled "The Role of Extracranial and Intracranial Arteries in Cerebral Infarction" aortic valve at the level of the third dorsal vertebra ; the subclavian arteries were divided beyond the origin of the vertebral arteries and the major vessels were then mobilized. After sectioning the cervical spine at the level of the seventh cervical vertebra a saw cut was made through the base of the skull on a line which ran through the anterior, middle, and posterior fossae on both sides. This provided a specimen containing the aorta and the neck vessels throughout their entire course. The carotid arteries were then exposed in the carotid canal with bone forceps. After examination of the arch of the aorta, the innominate artery, the common and internal carotid arteries, the subclavian artery, and the extravertebral part of the vertebral artery were examined by transverse section at $1-\mathrm{cm}$. intervals throughout their course. The cervical spine was decalcified with $10 \%$ hydrochloric acid and after three weeks the vertebral portion of the vertebral artery was exposed and examined.

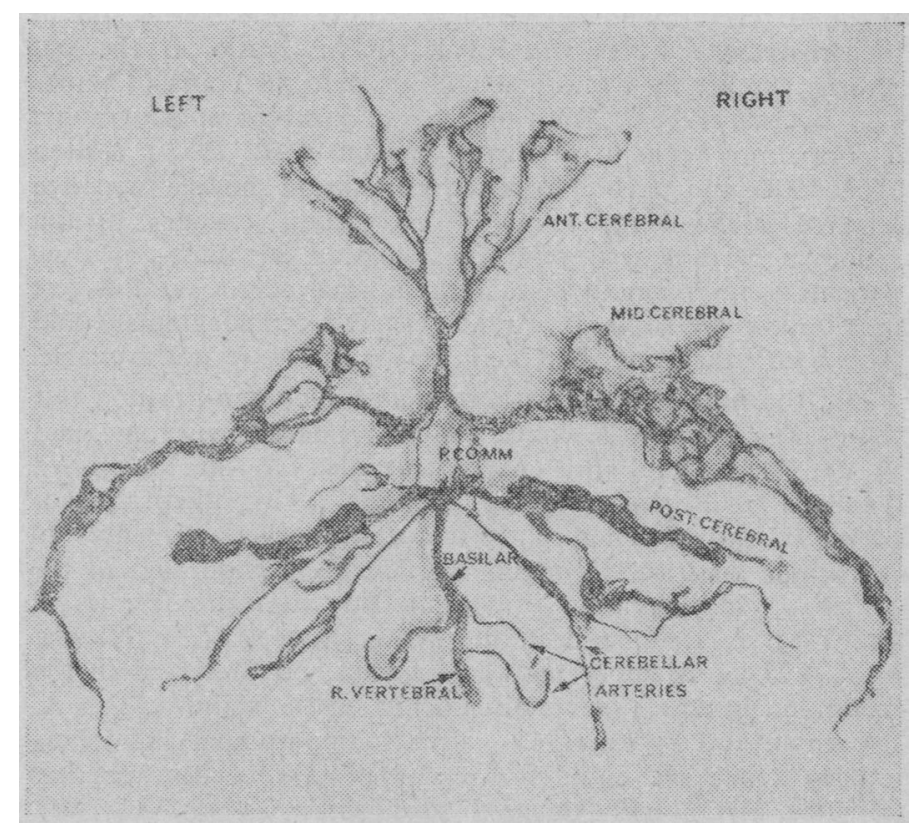

FIG. 1.-Specimen showing the intracranial vessels dissected from the brain preparatory to examination for stenosis and occlusion. 
After fixation of the brain the remainder of the cerebral arteries were dissected free with blunt forceps. The circle of Willis, the basilar artery, and the arteries to the cerebellum and brain stem were first freed; the dissection was then continued and the major branches of the circle of Willis-the anterior, middle, and posterior cerebral arteries-were removed from the hemispheres (Fig. 1). The whole specimen was then floated in water for examination, and the extent of atheroma and degree of stenosis of vessels from their origin to their termination in the gyri were noted. The brain was examined by serial coronal sections $1 \mathrm{~cm}$. thick and the extent of macroscopic infarction charted on a diagram.

In each specimen the vascular changes were classified in the following manner. The distribution of the arterial lesion was first noted on an outline diagram of the vascular supply. The nature of the vascular change was then recorded-that is, fatty streaks, fibrous plaques, plaques with softening, intramural haemorrhage, calcification-ulceration of the surface of the lesion and thrombus were noted separately. The degree of stenosis was classified as follows: grade 0 , no encroachment on the lumen; grade 1 , less than $25 \%$ reduction of lumen; grade 2,25 to $50 \%$ reduction of lumen; grade 3, more than $50 \%$ reduction of lumen but no occlusion; grade 4, total occlusion.

Results

\section{Age and Sex Distribution}

The age distribution in the infarct and control groups is shown in Table I. At death only 3 of the 57 with infarcts were below 60 , whereas 22 of the 88 controls were between 40 and 60 . In contrast, 15 with infarcts and only six controls were over 80 at death. The average age of the infarct group at death was 72.4 years, compared with 62 years in the control group. However, $68 \%$ of the patients in both the infarct and the control group were between 60 and 80 years of age at death.

TABLE I.-Distribution by Age at Death and Sex of 57 Patients with \begin{tabular}{l|c|c|c|c|c|c|c}
\multicolumn{7}{c}{ Infarcts and of 88 Controls } \\
\hline Age Group: & $40-49$ & $50-59$ & $60-69$ & $70-79$ & $80-89$ & $90+$ & Total \\
\hline
\end{tabular}

\begin{tabular}{|c|c|c|c|c|c|c|c|c|}
\hline \multirow[b]{2}{*}{$\begin{array}{l}\text { Male } \\
\text { Female }\end{array}$} & \multicolumn{8}{|c|}{ Infarcts } \\
\hline & $\ldots$ & -1 & 2 & $\begin{array}{r}10 \\
6\end{array}$ & $\begin{array}{l}12 \\
11\end{array}$ & $\begin{array}{l}6 \\
6\end{array}$ & $\begin{array}{l}1 \\
2\end{array}$ & $\begin{array}{l}31 \\
26\end{array}$ \\
\hline Total & $\ldots$ & 1 & 2 & 16 & 23 & 12 & 3 & 57 \\
\hline
\end{tabular}

\begin{tabular}{rr|r|r|r|r|r|r|r} 
Male & $\cdots$ & 2 & 12 & 25 & 8 & 3 & 0 & 50 \\
Female & $\cdots$ & 3 & 5 & 13 & 14 & 2 & 1 & 38 \\
\hline Total &. & 5 & 17 & 38 & 22 & 5 & 1 & 88 \\
\hline
\end{tabular}

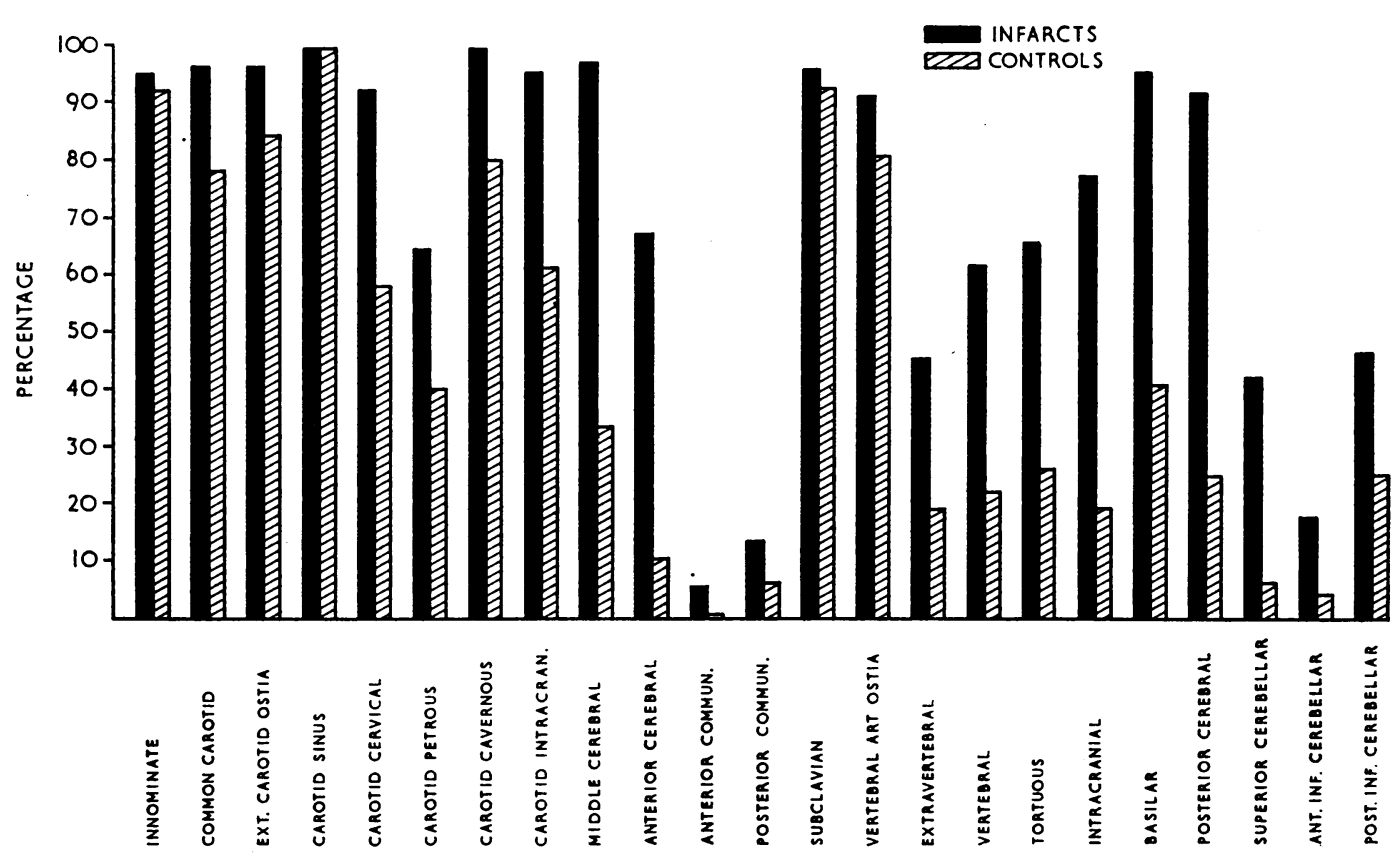

FIG. 2.-Distribution of all macroscopic vascular changes of the extracranial and intracranial vessels of the right side.

For each specimen the vascular change was recorded at multiple sites. In the carotid circulation the innominate artery, the common carotid, the external carotid ostia, the carotid sinus, and the cervical, cavernous, petrous, and intracranial portions of the carotid proximal to its primary division within the skull were assessed separately. In the vertebral circulation the subclavian, the vertebral artery ostia, the extravertebral portion of the artery, and the vertebral, tortuous, and intracranial parts of the vertebral artery were noted individually. The other intracranial arteries were scored according to the maximum degree of stenosis noted along the course of the individual vessel. For convenience, throughout the text the term "extracranial vessels" includes the terminal parts of the carotid and vertebral arteries within the skull. The term " intracranial vessels" refers to the branches of the carotid and vertebral arteries lying below the brain and within its substance.

All the dissections were done by one of us (S. K. B.) ; the vascular changes were assessed independently by the others (E. C. H. and A. J. M.), who were unaware of the state of the brain at the time of this assessment.

\section{Cerebral Infarction}

Because brain infarcts were frequently multiple, 130 separate areas of infarction were noted in the 57 specimens (Table II). In 12 cases $(21 \%)$ the infarcts were cortical, in $29(51 \%)$ they were subcortical, and in $16(28 \%)$ both the cortical and the subcortical areas were affected. Table II shows the distribution of infarcts, and it will be seen that there were 107 in the

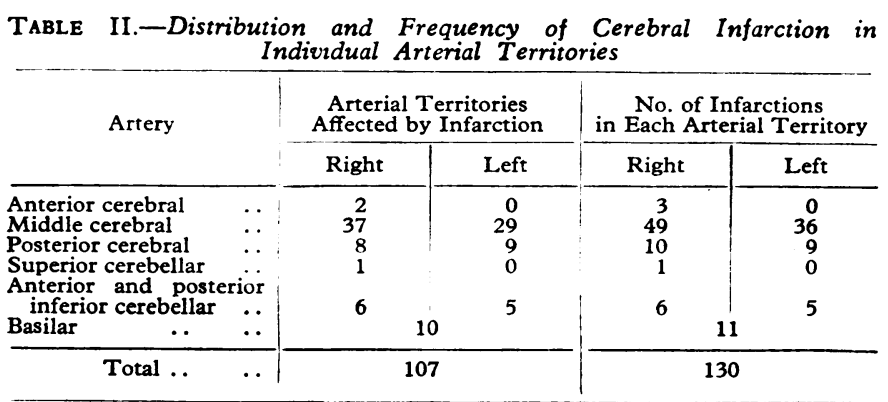


carotid and 23 in the vertebro-basilar territories. The middle cerebral territories were most often affected, and accounted for all but four of the areas of multiple infarction.

\section{l.esions in Cerebral Blood Supply}

This communication is primarily concerned with the prevalence of stenosis or occlusion of the cerebral arteries, but for the sake of completeness we have included in one illustration (liig. 2) all the macroscopic vascular lesions that were noted in the infarct and control groups. The figures are expressed as a percentage of the total in each group; the findings on the right and left sides are similar and, for the sake of brevity, the changes on the right side only are shown.

In the carotid circulation in the infarct and control groups the carotid sinus showed some change in all specimens. In the infarct group the innominate, the common carotid, and the cervical and cavernous portions of the carotid artery were also affected in over $90 \%$ of cases, and in the intracranial branches of the carotid artery the middle cerebral artery was affected to the same degree. In the control series there was a high incidence of vascular lesions at certain sites-for example, the innominate, the common carotid, the cavernous part of the carotid-but compared with the infarct group the changes in the cervical and petrous part of the carotid and in the anterior and middle cerebral vessels were considerably less.

The subclavian and vertebral artery ostia showed changes in over $80 \%$ of cases in both the infarct and control groups. In the infarct group the extravertebral portion of the vertebral artery was affected in $44 \%$, compared with $21 \%$ of the controls. There was also a higher incidence of lesions within the vertebral canal and in the tortuous and intracranial portions of the vertebral artery in the infarct compared with the control group. In the intracranial branches the incidence of vascular change in the posterior cerebral artery was $91 \%$ in the infarct group compared with $25 \%$ in the control group.

The lowest incidence of vascular change in both the infarct and the control groups was found in the anterior and posterior communicating arteries and in the anterior inferior cerebellar artery.

\section{Stenosis and Occlusion of Vessels}

The incidence and distribution of stenosis (grades 1 to 3 ) and occlusion of vessels (grade 4) in the two groups are shown in Table III. For simplicity of presentation the numbers observed in each grade are expressed as a percentage of the total in the infarct and control groups. Statistical assessment was made on the numbers in each grade in both groups. It was often necessary to combine grades 3 and 4 and sometimes grades 2,3 , and 4 in order to provide groups of sufficient size. The $\chi^{2}$ test was applied when three or more groups were combined, but for two groups the tables of Mainland et al. (1956) were used. The level of $P<0.05$ was accepted as significant.

When the extracranial vessels of the two groups were compared the innominate and subclavian arteries were the only vessels in the infarct group which failed to reach this level of significance when compared with the control group. Of the intracranial vessels the anterior inferior cerebellar and the communicating arteries were the only vessels in the infarct group which failed to show a significantly higher incidence of stenosis when compared with the controls.

If a severe degree of stenosis (grade 3 ) is considered in isolation certain points of interest arise. In the left carotid sinus the incidence of grade 3 stenosis is the same in the control and the infarct group ( $5 \%$ ), and in the left cavernous sinus the incidence is slightly higher in the controls (3\%) than in the infarcts $(2 \%)$. Elsewhere the incidence of grade 3 stenosis is always higher in the extracranial vessels of the infarct group. The differences are more pronounced in certain intracranial vessels. The middle cerebral artery, for example, showed grade 3 stenosis in $33 \%$ of cases on the right side compared with an incidence of $5 \%$ in the controls. Less marked but still significant differences 'were found in the anterior and posterior cerebral arteries and in the posterior inferior cerebellar arteries. In spite of the higher incidence of stenosis in the infarct group it is worth emphasizing that grade 2 stenosis was frequently observed in the control group.

\section{Occlusion of Vessels}

One striking difference in vascular lesions between the two groups was that occlusion of vessels was confined to the infarct group. Occlusion of the carotid arteries was found on 64 occasions and occlusion of the vertebral arteries on 30. Of the 64 carotid occlusions, 42 were on the right and 22 on the left side ; of the 30 vertebral occlusions, 16 were on the right and 14 on the left. In the intracerebral vessels occlusion was

TABI.: III.-Distribution of Occlusion and Different Grades of Stenosis in the Infarct and Control Groups. The Figures are Expressed as a Percentage of the Total Cases in the Infarct and Control Groups

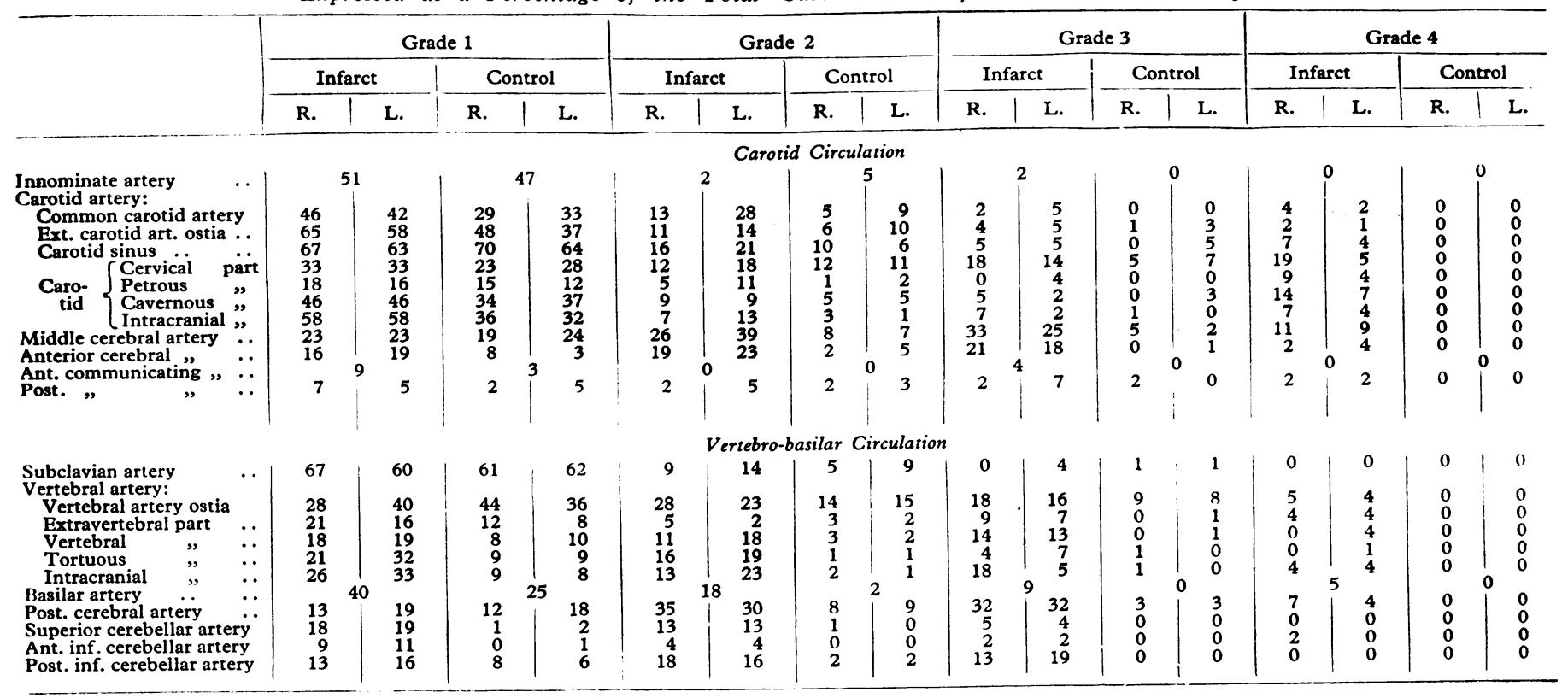


found in 28 brains. The middle cerebral artery accounted for 11 , the posterior cerebrals for 8 ; of the remainder the basilar and anterior cerebral were occluded three times, the communicating arteries twice, and the anterior inferior cerebellar once. In the paired intracranial vessels there was no predilection for either side.

\section{"Stenosis Score"}

A comparison of the extent of vascular disease in groups of vessels poses certain problems. A score of 0 to 4 may be allotted according to the maximum change noted along the course of a vessel. This uncomplicated system was adopted in the present series for the comparison of the intracranial vessels, as we felt that the difference between the two groups was so pronounced as to require no further examination. There is, however, a serious disadvantage in using this method to compare the larger cervical vessels in that a comparatively normal vessel occluded by embolus will score more than a vessel diffusely involved throughout its length. In order to avoid this emphasis on a localized site of disease the carotid and vertebral arteries in the two groups were compared by using a scoring system which took into account the findings at all sites examined. In each specimen scores from 0 to 4 were recorded at 27 sites distributed over the innominate, subclavian, carotid, and vertebral arteries, as previously described. In the extreme case of occlusion of all major vessels throughout their course a score of $108(27 \times 4)$ would be allotted. In order to minimize the effect of the difference in age distribution, the infarct and control series were divded into decades.

The stenosis score shown in Table IV is the total score for each decade expressed as a percentage of the maximum possible score for that decade. The results indicate that in the infarct group the stenosis score for the extracranial vessels was twice that observed in the controls. The only exception to this was in the over-90 age group, where only one patient was concerned in the controls. It should be noted that there were only three patients below the age of 60 in the infarct group compared with 22 controls, and therefore direct comparison between the two groups in these decades is not valid. However, $68 \%$ of the patients in both groups lie in the 60-80 age range, and the stenosis score for the extracranial vessels of the infarct group was over twice that of the controls. In these two decades the intracranial stenosis score for the infarct group was between three and six times more than that noted in the control group.

TABLE IV.-Comparison of the "Stenosis Score" (see Text for Definition) in the Major Neck Vessels and the Intracranial Vessels of the Infarct and Control Groups. The Figures in Parentheses are the Number of

\begin{tabular}{|c|c|c|c|c|c|c|}
\hline Age: & $40-49$ & $50-59$ & $60-69$ & $70-79$ & $80-89$ & $90+$ \\
\hline \multicolumn{7}{|c|}{ Extracranial Vessels } \\
\hline $\begin{array}{l}\text { Infarct .. } \\
\text { Control }\end{array}$ & $\begin{array}{l}\text { (1) } 27 \cdot 8 \% \\
\text { (5) } 8 \cdot 7 \%\end{array}$ & $\mid \begin{array}{ll}(2) & 36 \cdot 2 \\
(17) & 12 \cdot 5\end{array}$ & $\begin{array}{l}\text { 16) } 29 \cdot 4 \\
\text { 38) } 12.5 \\
\text { racranial }\end{array}$ & $\begin{array}{l}\text { (23) } 24 \cdot 2 \% \\
\text { (22) } 10 \cdot 8 \% \\
\\
\text { essels }\end{array}$ & (12) $18.0 \%$ & $\begin{array}{l}\text { (3) } 25 \cdot 6 \% \\
\text { (1) } 24.0 \%\end{array}$ \\
\hline $\begin{array}{l}\text { Infarct ... } \\
\text { Control }\end{array}$ & $\begin{array}{c}20.3 \% \\
1 \%\end{array}$ & $\begin{array}{r}33.5 \% \\
3.8 \%\end{array}$ & $\begin{array}{c}28.9 \% \\
4.3 \%\end{array}$ & $\begin{array}{r}21.6 \% \\
5.9 \%\end{array}$ & $\begin{array}{r}22 \cdot 8 \% \\
5.7 \%\end{array}$ & $\begin{array}{l}29 \% \\
10 \%\end{array}$ \\
\hline
\end{tabular}

\section{Multiple Involvement of Cervical Vessels}

It is now generally appreciated that when one of the four major cervical vessels is affected by atheroma it is highly probable that one or more of the remaining three vessels will show similar changes. In our material we examined this point in relation to severe stenosis (grade 3 ) and occlusion in both the control and the infarct series and compared the two groups. Table $\mathrm{V}$ shows the incidence in both groups, and the results are tabulated on the presence of grade 3 stenosis or occlusion in one, two, three, or four of the major vessels. It will be seen that in 17 of the 57 infarcts grade 3 stenosis or occlusion was found in all four vessels, whereas only 2 of the 88 controls showed grade 3 stenosis in all four vessels. In spite of this marked difference it is worth emphasizing that grade 3 stenosis was noted in one or more of the four vessels in 29 of the 88 controis. TABLE V.-Incidence of "Multiple" Involvement of Carotid and
Vertebral Arteries by Grade 3 Stenosis or Total Occlusion in the Infarct

\begin{tabular}{|c|c|c|c|c|c|}
\hline & 4 Vessels & 3 Vessels & 2 Vessels & 1 Vessel & Total \\
\hline \multicolumn{6}{|c|}{ Infarct } \\
\hline $\begin{array}{l}\text { Male .. } \\
\text { Female .. }\end{array}$ & $\left.\begin{array}{l}8 \\
9\end{array}\right\} 17$ & $\left.\begin{array}{r}14 \\
5\end{array}\right\} 19$ & $\left.\begin{array}{l}5 \\
5\end{array}\right\} 10$ & $\left.\begin{array}{l}3 \\
5\end{array}\right\} 8$ & 54 \\
\hline \multicolumn{6}{|c|}{ Control } \\
\hline $\begin{array}{l}\text { Male } \\
\text { Female } .\end{array}$ & $\left.\begin{array}{l}1 \\
1\end{array}\right\}^{2}$ & $\left.\begin{array}{l}2 \\
0\end{array}\right\} 2$ & $\left.\begin{array}{l}4 \\
2\end{array}\right\} 6$ & $\left.\begin{array}{r}5 \\
14\end{array}\right\} 19$ & 29 \\
\hline
\end{tabular}

\section{Correlation of Extracranial and Intracranial Vascular Disease}

An attempt was made to examine quantitatively the relation between extracranial and intracranial stenosis. For this purpose attention was paid only to the maximum stenosis in a particular vessel, and the intracranial and extracranial vessels were scored from 0 to 4 according to the degree of stenosis.

Product/moment correlation coefficients ( $r$ ) were calculated as follows: control group (88 cases), $r=0.2246$; infarct group ( 57 cases), $\mathrm{r}=0.139$.

The coefficients are statistically significant in the control group $(\mathrm{P}<0.05)$ but not in the infarct group (Fisher, 1946).

\section{Discussion}

The frequency of multiple involvement by atheroma of the carotid and vertebral arteries and the high incidence of stenosis at the carotid sinus and in the cavernous part of the carotid artery observed in the present study have been noted by previous observers. There are minor differences in the distribution of the arterial lesions as compared with previous work. McGee et al. (1962), for example, found that the vertebral artery within the vertebral canal was the commonest site for stenosis in the vertebral circulation, whereas in the present series the vertebral artery ostia showed the highest incidence. Schwartz and Mitchell (1961) found a higher incidence of stenosis at the carotid sinus relative to the cervical part of the carotid artery than we observed. Nevertheless the pattern of vascular disease in the carotid and vertebral arteries is in broad agreement with the findings of previous observers (Hutchinson and Yates, 1957 ; Martin et al., 1960 ; Schwartz and Mitchell, 1961; McGee et al., 1962).

In this paper we have not attempted to analyse the mechanism of infarcts as we are preparing a further communication on this subject, but thrombosis or embolic occlusion of neck vessels is clearly of crucial importance. The speed with which occlusion occurs may leave no time for the development of an adequate collateral circulation, and the lesion itself provides a possible source of emboli that may occlude the cerebral vessels.

Fisher (1954), in a clinical and pathological study of carotid artery disease, emphasized the importance of thrombi arising at the carotid bifurcation as a cause of embolic infarction. More recently attention has been focused on episodes of cerebral ischaemia due to platelet emboli arising from the carotid artery. Millikan and Siekert (1955) first suggested that a cerebral embolus may fragment, and pass through the cerebral circulation, causing only transient cerebral ischaemia. Clinical observations on the optic fundi, where small emboli were seen to pass through the retinal circulation without causing permanent retinal damage, supported this suggestion (Fisher, 1959 ; Russell, 1961 ; Ashby et al., 1963). The suggestion that 
these emboli may be a small aggregation of platelets (DennyBrown, 1960) was confirmed by the pathological study of McBrien et al. (1963). It is uncertain how frequently emboli of this type may be responsible for transient ischaemic episodes, but Gunning et al. (1964) suggested that these microemboli, composed largely of platelets and leucocytes and arising from an atheromatous internal carotid artery, were a common cause of repeated attacks of monocular blindness and contralateral hemiparesis.

The significance of stenosis alone-uncomplicated by thrombosis-as a cause of cerebral infarction has been increasingly questioned. The high incidence of neck-vessel stenosis in persons with infarct-free brains was pointed out by Schwartz and Mitchell (1961) and is apparent in our material. Hypotensive episodes may produce cerebral infarction (Adams et al., 1966), and it is very probable that vascular stenosis may, on occasion, increase the likelihood of infarction from hypotension. The importance of episodic hypotension associated with cerebral vascular disease in causing transient cerebral ischaemia has been convincingly argued by Denny-Brown (1951) and supported by Williams and Wilson (1962). Millikan (1965), however, questioned the importance of both episodic hypotension and neck-vessel stenoses as a frequent cause of transient cerebral ischaemia. It is relevant that Vost et al. (1964) found no evidence that hypotensive episodes contribute in any of the 255 cases of cerebral infarction they examined at necropsy.

The observations of Brice et al. (1964) have also discouraged the suggestion that uncomplicated carotid stenosis may determine infarction. They carried out in-vivo experiments on 13 patients and also made observations using an excised carotid artery in a constant-flow perfusion circuit. They found that the lumen had to be reduced to 2 sq. $\mathrm{mm}$. before significant reduction in flow occurred. They concluded that with a residual cross-section of 5 sq. $\mathrm{mm}$. or more a reduction in flow was very unlikely, even when there were stenoses in series. Our results and those of other observers (Martin et al., 1960 ; Schwartz and Mitchell, 1961 ; McGee et al., 1962) all indicate that multiple severe stenoses of the cerebral blood supply may be present in the absence of cerebral infarction. Confirmatory observations were made during life by Faris et al. (1963), who studied 43 volunteers who had no clinical or historical evidence of cerebral vascular disease. Arch aortograms were carried out and in half the subjects some form of arterial lesion was shown in the carotid or the vertebral arteries and more than one vessel was affected in $10 \%$ of the subjects.

Not only may there be lack of association between extracranial stenosis and cerebral infarction, but there may also be a lack of correlation between the symptomatology and the site of arterial disease. This point was made by Sutton and Davies (1966), who reported their findings in 330 patients who were referred to them with a clinical diagnosis of cerebral vascular insufficiency and who were examined by arch aortography. They found that in patients with symptoms of basilar artery insufficiency radiological abnormalities were found in only $52 \%$, and that lesions were noted as frequently in the carotid as in the vertebral circulation.

In our material the method we adopted for examining the intracranial arteries enabled us to define precisely the degree of stenosis in each of these vessels, and our analysis throws further light on the significance-or lack of significance-of arterial stenosis in relation to infarction. We found that cerebral infarction was most common in the middle cerebral artery territory and a severe degree (grade 3 ) of stenosis occurred in over $30 \%$ of these vessels. However, the posterior cerebral arteries showed grade 3 stenosis in a similar number of cases, whereas the incidence of infarction in the posterior cerebral territory was considerably less than that noted in the middle cerebral territories. The anterior cerebral artery also showed an appreciable incidence of grade 3 stenosis, for, on the right side, it was noted in one in five subjects in the infarct group and yet infarction was observed only three times in this arterial territory.

Cerebral infarction is a dynamic process with several possible contributory causes, and therefore a pathological study of the type reported will do no more than permit a partial appraisal of the pathogenesis. However, we believe that our findingsparticularly those in relation to the intracranial vessels-do not support the view that stenosis alone plays a decisive part in the pathogenesis of cerebral infarction. The high incidence of infarction in the middle cerebral territories, together with an appreciable incidence of vascular change in other intracranial vessels, suggests that emboli may have an even more important part to play than has been recognized previously. We intend to examine our material further with this point in mind.

\section{Summary}

The necropsy findings in 57 patients with cerebral infarction and 88 controls are compared.

In the 57 brains, 130 separate areas of infarction were found.

The distribution of vascular disease in the cerebral blood supply is described in both the infarct and the control group. Occlusion of the cerebral arteries was confined to the infarct group and the incidence of stenosis in this group is significantly higher than in the controls.

The results suggest that uncomplicated stenosis is not a decisive factor in the development of cerebral infarction.

We wish to acknowledge the encouragement and advice of Professor J. W. Orr and the generous financial support of the Research Subcommittee of the Birmingham Regional Hospital Board throughout this investigation. We are grateful to H.M. Coroners, Mr. F. G. Hails and Mr. J. S. Marshall, for permission to make use of certain material.

\section{REFERENCES}

Adams, J. H., Brierley, J. B., Connor, R. C. R., and Treip, C. S. (1966). Brain, 89, 235.

Ashby, M., Oakley, N., Lorentz, I., and Scott, D. (1963). Brit. med. F., 2, 894.

Brice, J. G., Dowsett, D. J., and Lowe, R. D. (1964). Ibid., 2, 1363.

Denny-Brown, D. (1951). Med. Clin. N. Amer., 35, 1457.

- (1960). Arch Neurol. (Chic.), 2, 194.

Duffy, P. E., and Jacobs, G. B. (1958). Neurology (Minneap.), 8, 862.

Faris, A. A., Poser, C. M., Wilmore, D. W., and Agnew, C. H. (1963). Ibid., 13, 386.

Fisher, C. M. (1954). Arch. Neurol. Psychiat., 72, 187.

Fisher, (1959). Neurology (Minneap.) 9, 333.

Fisher, R. A. (1946). Statistical Methods for Research Workers, 10th ed., p. 209. Edinburgh.

Gunning, A. J., Pickering, G. W., Robb-Smith, A. H. T., and Russell, R. R. (1964). Quart. F. Med., 33, 155.

Hutchinson, E. C., and Yates, P. O. (1957). Lancet, 1, 2.

McBrien, D. J., Bradley, R. D., and Ashton, N. (1963). Ibid., 1, 697.

McGee, D. A., McPhedran, R. S., and Hoffman, H. J. (1962). Neurology (Minneap.) 12,848 .

Mainland, D., Herrara, L., and Sutcliffe, H. I. (1956). Tables for Use with Binomial Samples. New York.

Martin, M. J., Whisnant, J. P., and Sayre, G. P. (1960). Arch. Neurol. (Chic.), 3, 530

Millikan, C. H. (1965). Circulation, 32, 438

Millikan, C. H. (1965). Circulation, 32, 438. Clin. 30, 61.

Russell, R. W. R. (1961). Lancet, 2, 1422 .

Schwartz, C. J., and Mitchell, J. R. A. (1961). Brit. med. 7., 2, 1057

Sutton, D., and Davies, E. R. (1966). Clin. Radiol., 17, 330.

Vost, A., Wolochow, D. A., and Howell, D. A. (1964). F. Path. Bact, $88,463$.

Williams, D., and Wilson, T. G. (1962). Brain, 85, 741. 